\title{
Heated High-Flow Nasal Oxygen for the Treatment of Severe Hypothermia: Case Report
}

\author{
Angela Saviano ${ }^{1}$, Marcello Candelli*1, Giulio De Luca ${ }^{1}$, Giulia Pignataro ${ }^{1}$, Carmine Petruzziello ${ }^{1}$, \\ Simone M Navarra ${ }^{1}$, Veronica Ojetti ${ }^{1}$, Marcello Covino ${ }^{1}$, Mariano Pennisi ${ }^{2}$ and Francesco Franceschi ${ }^{1}$
}

${ }^{1}$ Department of Emergency Medicine, Italy

${ }^{2}$ Department of Anesthesiology, Italy

*Corresponding author: Marcello Candelli, Department of Emergency Medicine, Fondazione Policlinico A Gemelli IRCCS, Italy

ARTICLE INFO

Received: 幽 August 30, 2019

Published: 慧 September 09, 2019

Citation: Angela Saviano, Marcello Candelli, Giulio De Luca, Giulia Pignataro, Carmine Petruzziello, et al. Heated HighFlow Nasal Oxygen for the Treatment of Severe Hypothermia: Case Report. Biomed J Sci \& Tech Res 21(2)-2019. BJSTR. MS.ID.003566.

Abbreviations: CT: Computed Tomography; IV: Intravenous; ECMO: Extracorporeal Membrane Oxygenation; CPB: Cardiopulmonary Bypass

\begin{abstract}
Hypothermia is a condition in which the core temperature drops below $35^{\circ} \mathrm{C}\left(95^{\circ} \mathrm{F}\right)$. It is a medical emergency with a high morbidity and mortality rate. Beyond an excessive cold exposure, many medical conditions can be associated with hypothermia as hypothalamic dysfunction, hypopituitarism, hypoadrenalism, hypoglycemia, malnutrition, subarachnoid hemorrhage, cerebrovascular accidents, toxins, ethanol abuse, Parkinson's disease, lactic acidosis, neuropathy, spinal cord lesions, trauma, severe infections, drugs and neoplasms. We report a case of an 82-years old woman with bradycardia due to severe hypothermia. She was treated successfully with heated high-flow nasal oxygen and warmed intravenous fluids. She recovered from bradycardia without needed a permanent pacemaker, but the etiology of her hypothermia remained unexplained. Early selection of an appropriate rewarming technique in the Emergency Department is essential to improve the prognosis of patients with hypothermia, prevent complications and avoid mistakes in the choice of therapy.
\end{abstract}

Keywords: Hypothermia; Bradycardia; Osborne Wave; Medical Emergency; Rewarming Technique; High-Flow Nasal Oxygen

\section{Introduction}

Hypothermia is a harmful condition associated with possible unfavorable outcomes. Literature data revealed a mortality of about $40 \%$ [1]. It is responsible of cardiovascular, respiratory and neurological failure. Electrocardiogram changes, including bradycardia, are common findings during progressive hypothermia [2]; it may be the expression of a breakdown in the compensatory mechanisms of the body and of the progressive decline of vital functions. In the Emergency Department, the available therapeutic strategies are not always effective and new treatments need to be designed. Our case report would show a possible advantageous treatment opportunity in patients with hypothermia.

\section{Case Report}

An 82-years old woman was admitted to our Emergency Department because of drowsiness, sudden slurred speech and bradycardia (heart rate of 32 beats/min). Her blood pressure was $115 / 60 \mathrm{~mm} / \mathrm{Hg}$, respiratory rate 14 breaths/minute, oxygen saturation $89 \%$ breathing ambient air, and cutaneous temperature was $33.4^{\circ} \mathrm{C}$. On physical examination, she was alert, not oriented to time and place, not shivering and with impaired psychomotor skills. Her past medical history was significant for hypertension and Hashimoto's thyroiditis. One years earlier, she was hospitalized for an ischemic stroke of the left frontal cortex due to congenital arteriovenous malformations. Her home drug therapy included levothyroxine, aspirin, doxazosin, perindopril, barnidipine, amlodipine, a low dose of carvedilol, bromazepam, pantoprazole, vitamin complex (B9, B12). We checked several blood parameters that revealed a C-reactive protein of $100 \mathrm{mg} / \mathrm{dl}$ (normal value < $5 \mathrm{mg} / \mathrm{dl}$ ), a TSH of $5.10 \mu \mathrm{U} / \mathrm{mL}$ (normal range 0.35-3.20 $\mu \mathrm{U} / \mathrm{mL}$ ), and a hemoglobin level of $9.5 \mathrm{~g} / \mathrm{dl}$. Liver, kidney function and blood coagulation tests resulted normal. 
Potassium resulted $3.1 \mathrm{mmol} / \mathrm{L}$ (normal range: $3.5-5.5 \mathrm{mmol} / \mathrm{L}$ ). The electrocardiogram revealed sinus bradycardia, prolonged QT interval, and not-specific repolarization abnormalities. The arterial blood gases showed hypoxemia and compensated chronic respiratory acidosis $\left(\mathrm{PaO}_{2}: 72.8 \mathrm{mmHg}, \mathrm{PaCO}_{2}: 54.5 \mathrm{mmHg}, \mathrm{pH}\right.$ : 7.401; $\mathrm{HCO}_{3}$-: $\left.31.5 \mathrm{mmol} / \mathrm{L}\right)$. She was evaluated by a cardiologist who prescribed an intravenous treatment with atropine. The neurologist investigated her neurological status with a computed tomography scan and a cerebral magnetic resonance that resulted negative for acute ischemic/hemorrhagic stroke and for brain tumors. The endocrinologist added hydrocortisone four times/ day, indicated blood dosage of cortisol levels that resulted $272 \mathrm{ng} /$ $\mathrm{mL}$ (normal range $60-220 \mathrm{ng} / \mathrm{mL}$ ), and recommended a thorax CT scan that resulted negative for pulmonary embolism and lung tumors, revealing only a little centrilobular emphysema. We placed an esophageal probe that showed a temperature of $31.4^{\circ} \mathrm{C}$ and we started treatment with warmed IV fluids. After few hours, we measured body temperature with a bladder catheter sensor with a value of $30.1^{\circ} \mathrm{C}$. We started treatment with heated high-flow nasal oxygen (Optiflow) with a surprising improvement of cutaneous temperature until $36^{\circ} \mathrm{C}$ and beneficial effects on her general clinical conditions.

\section{Discussion}

The normal human body temperature is $36.5-37.5^{\circ} \mathrm{C}[2]$. Hypothermia is a medical emergency with a high morbidity and mortality rate. It is responsible of cardiovascular, respiratory and neurological impairment $[3,4]$ with hypoxia, hyporeflexia, hypoventilation, central nervous system depression and cardiac arrest [5-7]. The Swiss staging system [8-10] recognizes four stages of hypothermia, based on vital signs and clinical symptoms. Stage I includes alert, conscious and shivering patients with a temperature between 35 and $32^{\circ} \mathrm{C}$; stage II includes patients with an impaired level of consciousness, not shivering and with a temperature between 32 and $28^{\circ} \mathrm{C}$; stage III includes unconscious, not shivering patients with vital signs and with a temperature between 28 and $24^{\circ} \mathrm{C}$; in stage IV vital signs are absent but resuscitation may be possible; the stage over this last corresponds to "irreversible" death.

Emergency medical treatment for hypothermia may include covering with clothes, offering warmed rooms and drinks, encouraging movements (for stage I); resuscitation with intravenous warmed fluids, cardiovascular monitoring, immobilization to prevent arrhythmias, ECMO, CPB, in case of cardiac instability (for stage II-III); finally, management with epinephrine, invasive rewarming techniques, ECMO, CPB, defibrillation, advanced cardiopulmonary resuscitation are needed for stage IV [8]. High-flow nasal oxygen (Optiflow) should be evaluated for the management of hypothermia because it may provide some beneficial effects.
The constant high-flow oxygen is able to increase intra-alveolar volumes [11] preventing alveolar closure, decrease the anatomical respiratory dead space, improved the clearance of secretions and decrease the thoraco-abdominal work of breathing [11], preventing hypoxemia and hypoventilation due to hypothermia and improving central and peripherical oxygenation and heart performance.

\section{Conclusion}

Hypothermia is a life-threating condition that can lead to death [12]. The selection of an appropriate rewarming technique in the Emergency Department is essential to improve the prognosis of patients with hypothermia, preventing complications as hypoxia and cardiac arrest and consequently, improving the survival. We reported a case of hypothermia treated successfully with heated high-flow nasal oxygen. To date, the "gold standard" treatment is not known but physicians should choose a reasonable approach guided by clinical and medical patients' responses.

\section{Conflict of Interest}

All authors declared no conflict of interest.

\section{References}

1. Vassal T, Benoit Gonin B, Carrat F, Guidet B, Maury E, et al. (2001) Severe accidental hypothermia treated in an ICU: prognosis and outcome. Chest 120(6): 1998-2003.

2. Doshi HH, Giudici MC (2015) The EKG in hypothermia and hyperthermia. J Electrocardiol 48(2): 203-209.

3. Vassallo SU, Delaney KA, Hoffman RS, Slater W, Goldfrank LR, et al. (1999) A prospective evaluation of the electrocardiographic manifestations of hypothermia. Acad Emerg Med 6(11): 1121-1126.

4. Zafren K, Giesbrecht GG, Danzl DF, Brugger H, Sagalyn EB, et al. (2015) Hypothermia Evidence, After drop, and Guidelines. Wilderness Environ Med 26(3): 439-441.

5. Epstein E, Anna K (2006) Accidental hypothermia. BMJ 332(7543): 706709.

6. Jolly BT, Ghezzi KT (1992) Accidental hypothermia. Emerg Med Clin North Am 10(2): 311-327.

7. Hanania NA, Zimmerman JL (1999) Accidental hypothermia. Crit Care Clin 15(2): 235-249.

8. Brown DJ, Brugger H, Boyd J, Paal P (2012) Accidental hypothermia. N Engl J Med 367(20): 1930-1938.

9. Paal P, Gordon L, Strapazzon G, Brodmann Maeder M, Putzer G, et al. (2016) Accidental hypothermia-an update: The content of this review is endorsed by the International Commission for Mountain Emergency Medicine (ICAR MEDCOM). Scand J Trauma Resusc Emerg Med 24(1): 111.

10. Gordon L, Ellerton JA, Paal P, Peek GJ, Barker J, et al. (2014) Severe accidental hypothermia. BMJ 348: 1675.

11. Helviz Y, Einav S (2018) A Systematic Review of the High-flow Nasal Cannula for Adult Patients. Crit Care 22(1): 71.

12. Headdon WG, Wilson PM, Dalton HR (2009) The management of accidental hypothermia. BMJ 338: 2085. 
ISSN: 2574-1241

DOI: 10.26717/BJSTR.2019.21.003566

Marcello Candelli. Biomed J Sci \& Tech Res

(c) (P) This work is licensed under Creative

Submission Link: https://biomedres.us/submit-manuscript.php

$\begin{array}{ll}\text { BIOMEDICAL } & \text { Assets of Publishing with us } \\ \text { RESEARCHES } & \text { Global archiving of articles } \\ \text { - Immediate, unrestricted online access } & \text { - Rigorous Peer Review Process } \\ & \text { - Authors Retain Copyrights }\end{array}$

